\title{
Relationship between the average slope in the active commuting to and from school and fitness in adolescents: the mediator role of fatness
}

\author{
Pedro Antonio Sánchez Miguel ${ }^{\text {Corresp., } 1}$, David Sánchez Oliva ${ }^{2}$, Mikel Vaquero Solís ${ }^{1}$, Juan J. Pulido ${ }^{2}$, Miguel Angel \\ Tapia Serrano ${ }^{\text {Corresp. } 1}$ \\ ${ }^{1}$ Department of Didactics of Musical, Plastic and Body Expression. Faculty of Teaching Training, University of Extremadura, Cáceres, Spain \\ 2 Department of Didactics of Musical, Plastic and Body Expression. Faculty of Sports Sciences, University of Extremadura, Cáceres, Spain
}

Corresponding Authors: Pedro Antonio Sánchez Miguel, Miguel Angel Tapia Serrano

Email address: pesanchezm@unex.es, matapiase@unex.es

Active commuting to and from school has been recognized as a potential tool to improve physical fitness. Thus, this study aims to test the relationships between the average slope in the active commuting to and from school and physical fitness, as well as to verify the mediator role of fatness in the relationship between average slope and physical fitness. A total of 257 participants, 137 boys and 120 girls, from 22 schools belonged to $1^{\text {st }}$ and $2^{\text {nd }}$ High School grades participated in this study. Based on self-reported measure and Google Earth, participants were grouped into the active commuter (number of trips was $\geq 5$, and the time of the trip was $\geq 15$ minutes), mixed commuter (number of weekly trips was $<5$, and the time spent on the trip was $<15$ minutes) and passive commuter groups (those who reported traveling regularly by car, motorcycle, or bus). Specifically, in the active commuter group, a positive association between the average slope in the active commuting to and from school with fatness was found, which in turn was positively related to strength lower limbs and cardiorrespiratory fitness. The average slope was not significantly associated with physical fitness indicators. Furtheremore, fatness did not mediate the relathionship between average slope and physical fitness. This research concluded positive associations between average slope and the body fat in the active commuting to and from school. The tendency of findings signal that the average slope should be taken into account along with the distance, time and frequency of the active commuting. 
1 Relationship between the average slope in the active commuting to and from school and

2

3 Pedro Antonio Sánchez-Miguel ${ }^{1}$, David Sánchez-Oliva ${ }^{2}$, Mikel Vaquero-Solís $^{1}$, Juan J. Pulido ${ }^{2}$, 4 5

7 Training. University of Extremadura, Cáceres (Spain). Email: pesanchezm@unex.es;

8 mivaquero@alumnos.unex.es; matapiase@unex.es

9 and Miguel Angel Tapia-Serrano ${ }^{1}$

${ }^{1}$ Department of Didactics of Musical, Plastic and Body Expression. Faculty of Teaching 


\section{Abstract}

Active commuting to and from school has been recognized as a potential tool to improve

27 physical fitness. Thus, this study aims to test the relationships between the average slope in the

28 active commuting to and from school and physical fitness, as well as to verify the mediator role

29 of fatness in the relationship between average slope and physical fitness. A total of 257

30 participants, 137 boys and 120 girls, from 22 schools belonged to $1^{\text {st }}$ and $2^{\text {nd }}$ High School grades

31 participated in this study. Based on self-reported measure and Google Earth, participants were

32 grouped into the active commuter (number of trips was $\geq 5$, and the time of the trip was $\geq 15$

33 minutes), mixed commuter (number of weekly trips was $<5$, and the time spent on the trip was $<$

3415 minutes) and passive commuter groups (those who reported traveling regularly by car,

35 motorcycle, or bus). Specifically, in the active commuter group, a positive association between

36 the average slope in the active commuting to and from school with fatness was found, which in

37 turn was positively related to strength lower limbs and cardiorrespiratory fitness. The average

38 slope was not significantly associated with physical fitness indicators. Furtheremore, fatness did

39 not mediate the relathionship between average slope and physical fitness. This research

40 concluded positive associations between average slope and the body fat in the active commuting

41 to and from school. The tendency of findings signal that the average slope should be taken into

42 account along with the distance, time and frequency of the active commuting.

43 Keywords: active commuter, physical fitness, walking, body fat, adolescents and high

44 school. 


\section{Introduction}

Active commuting to and from school (ACS) can be defined as the mode of commuting

by which children or adolescents cover the distance between home and school, using a way that do not involve motorised vehicles, such as walking or cycling (Chillón et al., 2011; Larouche et al., 2014). In contrast, passive commuting refers to the use of motorised vehicles as a way of transport, such as car, bus, subway, train, motorcycle, or others (Villa-González et al., 2016a).

ACS has been recognized as a potential tool to increase daily physical activity or improve

physical fitness among adolescents (Larouche et al., 2014; Martin et al., 2016; Muntaner-Mas et al., 2018; Slingerland, Borghouts \& Hesselink, 2012).

Andersen et al. (2011) tested the benefits of this increase in adolescents, reporting lower levels of body fat and a lower probability of heart disease. In this regard, Ramírez-Vélez et al. (2017) showed that ACS was associated with greater physical fitness. Despite the clear benefits of physical activity and active school travel, recent evidence across 38 countries from six continents showed that only $20-39 \%$ of children and youth were adequately physically active for health (Tremblay et al., 2016). Recent researches have indicated a decrease of ACS in children and adolescence in worldwide (Chillón et al., 2013; Ministry of Transport, 2014; Yang, Ivey, Levy, Royne, \& Klesges, 2016). Due to this decrease, interest in the potential correlates of ACS has increased in the last years (Sallis et al., 2016; Rodríguez-Rodríguez et al., 2019). Trying to

64 find possible related factors, the systematic review conducted by Ikeda, Hinckson, Witten, \&

65 Smith (2018) found positive associations between ACS and perceptions of safety, walkability, 66 and neighbourhood social interaction, but any relationship in the average slope in the ACS at 67 school was found. In this regard, it has been shown that sections with an average slope are 
68 characterized by producing internal mechanical work, involving greater muscular activity and

69 increasing the linear energy demand (Ehrström et al., 2017; Vernillo et al., 2016).

70 In accordance to this issue, previous studies (Chillón et al., 2011; Muntaner-Mas,

71 Herrador-Colmenero, Borràs, \& Chillón, 2018) has highlighted the need to objectively quantify

72 the environmental characteristics of the routes because of the great variety of factors that

73 influence active commuting (for example: environmental characteristics, economic level of

74 families, use of information and communication technologies, family aspects, cultural

75 patterns...). However, few studies have focused on objectively quantifying physical

76 environmental attributes as the average slope during ACS at school (Batista, Cooper \& Audrey,

77 2018). The Geographic Information Systems (GIS) can be as a solution for this problem because

78 it has been showed that are valid and reliable instruments to assess the built environment (Veitch

79 et al., 2017) or connectivity between streets and pedestrian lanes (McCormack \& Shiell, 2011;

80 Muntaner-Mas et al., 2018).

81 In this line, as was previously indicated, it has been demonstrated that ACS can be a key

82 form of habitual physical activity (Larouche et al., 2014; Sallis et al., 2016). Furthermore, a

83 positive association with cardiorespiratory fitness in adolescents was shown in different

84 researches (Lubans et al., 2011; Muntaner-Mas et al., 2018). Nevertheless, there was a negative

85 relationship between ACS and body fat (Carson et al., 2016; Mytton, Panter \& Ogilvie, 2016).

86 Therefore, an indirect effect of fatness between relation positive slope of ACS and physical

87 fitness could be expected. However, up to our knowledge, there are none study that evaluated if

88 adiposity could affect in the associations between ACS and fitness components. Hence, the

89 present investigation proposed as aims: 1) to determine the relationship between the percentage

90 of the average slope in the ACS with physical fitness and 2) to verify if the fatness is a 
91 mechanism to explain the association between average slope and physical fitness. In accordance

92 with the aims indicated, several hypotheses are suggested. The first hypothesis suggested that the

93 active commuters would have a better physical fitness. The second hypothesis proposed that the

94 active commuters would have a lesser fatness and as a consequence would have a better physical 95 fitness.

96

\section{Materials and Methods}

\section{Design and Participants}

The present cross-sectional study was developed in the framework of the promote physical activity and healthy habits in adolescent's project developing in the extracurricular time (ClinicalTrials: NCT03974607, registered 19 August, 2019). Sample selection was purposeful. The baseline data were collected from March 2018 to June 2019 in the Extremadura (Spain). For the present study, a total of 22 schools were assessed, with a final sample of 257 adolescents aged 13 - 16 years $(13.20 \pm 0.05$ years) whom 137 were boys ( $13.25 \pm 1.03$ years) and 120 girls (13.15 \pm 0.81 years) were included with complete baseline data for anthropometric measures, physical fitness and ACS variables (mode, number of trips, distance, time and average school). In Figure 1, the sample selection diagram can be proved.

Parents and school supervisors were informed by letter about the nature and purpose of the study, and written informed consent was provided. The study was conducted in accordance with the Declaration of Helsinki, and the protocol was approved by the Ethics Committee of the University of Extremadura (892016).

**Please, insert Figure 1 here**

Figure 1. Flow chart of participants according to the mode of travel. 
113

114

115

116

117

118

119

120

121

122

123

124

125

126

127

128

130

131

132

133

134

135

\section{Instruments}

Anthropometrical data. Adiposity parameters were evaluated by anthropometric

techniques following standardized procedures. All adiposity measurements were performed

twice and the average was recorded. Triceps and subscapular skin-fold thickness were evaluated according to standard procedures (Harpenden; range, 0-80 mm; precision, 0,2 $\mathrm{mm}$ ). The

percentage of body fat was determined using the Slaughter equation. All anthropometrics

measurements were performed by the same research team, and each member was specialized in one test, with the aim to reduce possible measurement errors.

Lower limb strength. The standing long jump test was applied and highest score in centimetres was taken of the two attempts allowed. To perform the test, a tape measure and a non-slippery surface were necessary. This test has been shown to be valid (Castro-Piñero et al., 2009) and reliable (Artero et al., 2011) with children and adolescents.

Cardiorrespiratoty fitness. The 20-meter shuttle-run test was used to evaluate cardiorrespiratory fitness (Ruiz et al., 2011). This Course-Navette is a field-based test, which consisted in running from one line to another line located 20 meters away, changing the rhythm in function of a sound signal that increases progressively. The initial speed of the signal is 8.5 $\mathrm{km} / \mathrm{h}$, and it increases by $0.5 \mathrm{~km} / \mathrm{h}$ ( 1 minute equals 1 stage $)$. The test ends when the participant cannot reach the line at the same time as the audio signal for the second consecutive time or when the participant stops due to fatigue. Test performance requires a loudspeaker used to reproduce the sound signal and a 20-meter non-slippery surface. The test has been shown to be valid and reliable in children and adolescents (Artero et al., 2011; Castro-Piñero et al., 2009). We used the Leger formula to calculate the maximal oxygen consumption (cardiorrespiratory fitness, $\mathrm{ml} / \mathrm{kg} / \mathrm{min}$ ) (Leger et al., 1988). 
137 students to travel to and from school were calculated with two self-reported questions. The first

138 question asked how they usually traveled to school (i.e., from Monday to Friday) and the second

139 asked how they habitually returned from school (i.e., from Monday to Friday). The validity of

140 these questions has been previously shown to be an adequate method to determine ACS at school

141 in children and adolescents (Herrador-Colmenero et al., 2014; Mora-Gonzalez et al., 2017;

142 Muntaner-Mas et al., 2018). Moreover, participant's information about their home address was

143 asked in the questionnaire. This information was introduced into the Google Earth (Villa-

144 González et al., 2016b), as well as the address of the school, with the aim to obtain the distance,

145 time and average slope in the ACS in all participants who reported commuting on foot or bike. It

146 has to be noted that no student reported commuting by bike in this sudy. Finally, the participants

147 were classified in active commuter (number of trips was $\geq 5$, and the time of the trip was $\geq 15$

148 minutes), mixed commuter mixed commuter (number of weekly trips was $<5$, and the time spent

149 on the trip was $<15$ minutes) and passive commuter (those who reported traveling regularly by

150 car, motorcycle, or bus) (Herrador-Colmenero et al., 2014; Mora-Gonzalez et al., 2017;

151 Muntaner-Mas et al., 2018).

$152 \quad$ Statistical Analysis

153 The characteristics of the study sample are presented as means and standard deviations

154 (SD) or percentages. Furthermore, an analysis of variance for each dependent variable was

155 performed in order to know the differences between boys and girls, and also between active

156 commuter, mixed commuter, and passive commuter. Later, also was estimated post-hoc analysis

157 based on Bonferroni Test with the aim to analyze comparisons by pairs. 
159 (MLR) estimator was used which allows to non-normality of observations and can handle data

160 that are missing at random (Yuan \& Bentler, 2000). As chi-square $(\chi 2)$ values can be inflated and

161 suggest poor model fit with larger samples sizes, the following common goodness-of-fit were

162 considered to assess model fit: comparative fit index (CFI) (Bentler 1990), Tucker-Lewis Index

163 (TLI) (Bentler \& Bonett, 1980), Root Mean Square Error Of Approximation (RMSEA) (Steiger,

164 1990), and Standardized Root Mean Square Residual (SRMR). Values greater than 0.90 and 0.95

165 for the CFI and TLI were considered to reflect "reasonable" and "excellent" model fit,

166 respectively, and values smaller than 0.08 or 0.06 for the RMSEA and SRMR were considered to

167 reflect "reasonable" and "excellent" model fit, respectively, based on rules of thumb

168 conventional cut-off criteria (Browne \& Cudeck, 1993; Hu \& Bentler, 1999). Finally, in order to

169 test the indirect effects, the path model was re-estimated using bootstrapping resampling

170 procedures $(N=10,000)$ to compute 95\% Confidence Intervals (Preacher \& Hayes, 2008).

171

172

173

174

175

176

177

178

179

180

\section{Results}

Table 1 shows descriptives of the studied variables and differences by gender. Boys

showed lower levels of tricipital fold and body fat, as well as higher scores in cardiorrespiratory

fitness when comparing with girls (all, $p<0.001)$.

** Please, insert Table 1 here **

Table 1. Descriptive analysis of the study variables and sex differences

The hypothesized path model showed an excellent fit to the data: $\operatorname{MLR} \chi 2=88.316 ; \mathrm{df}=6$;

$p<001 ; \mathrm{CFI}=1.000 ; \mathrm{TLI}=1.000 ; \mathrm{RMSEA}=0.000(90 \% \mathrm{CI}=0.000,0.000) ; \mathrm{SRMR}=0.000$.

Figure 2 presents the direct associations between study variables. Average slope was negatively associated with body fat $(\beta=-0.146 ; p<0.001)$. Body fat was negatively and directly related with 
181 cardiorrespiratory fitness $(\beta=-0.281 ; p<0.001)$ and strenght lower limbs $(\beta=-0.371 ; p<0.001)$.

182 However, average slope was not significantly associated with either strenght lower limbs or

183 cardiorrespiratory fitness. As displayed in Figure 2, the model explained 9\% of variance from

184 cardiorrespiratory fitness, whereas $15 \%$ of of variance from strength of the lower limbs was

185 explained throught the model. Table 2 presents the indirect associations between study variables.

186 Body fat was not found a significant mediator in the association between average slope and 187 physical fitness $(p>0.05)$.

**Please, insert Figure 2 here**

189

Figure 2. Standardized solution of the model.

**Please, insert Table 2 here**

191

Table 2. Indirect effects.

192

\section{Discussion}

The current study aimed to examine the association between the average slope in the ACS and physical fitness, as well as evaluate the mediator role of fatness in this relathionship. The main finding of this study was the negative association between average slope in the ACS and body fat, which in turn was negatively related with the strength lower limbs and between average slope and cardiorrespiratory fitness and strength lower limbs in the active commuter groups.

In line with our results, many researches have shown a positive relationship between

ACS and physical fitness in children and adolescents (Larouche et al., 2014; Martin et al., 2016). relation with the first hypothesis, results of current research demonstrated a positive association 
204 between average slope and strength lower limbs and cardiorrespiratory fitness in active

205 commuter groups. Previous research has confirmed that improving adolescents'

206 cardiorrespiratory fitness and muscle strength affects their cardiovascular health (Andersen et al.,

207 2011; Carson et al., 2016; Lubans et al., 2011). Therefore, previous researchers (Chillón et al.,

208 2017) have found the ACS as a way to increase the level of weekly physical activity which in

209 turn is associated with a physical fitness in adolescents.

210 On the contrary, the studies conducted by Muntaner-Mas et al. (2018) and Villa-González

211 et al. (2015) found ACS (mainly walking) was not a sufficient stimulation to modify strength

212 lower limbs and cardiorrespiratory fitness in adolescents, with the exception of the strength

213 lower limbs in girls, although these differences were minimal (Villa-González et al., 2015). In

214 addition, it is important to note that active commuting to school has been considered an

215 important predictor of physical activity energy expenditure (Slingerland, Borghouts \& Hesselink,

216 2012). Chillón et al. (2017) found that walking to school implies about more than $7 \mathrm{~min}$ of

217 physical activity moderate and vigorous per day/journey in Spanish adolescents, respectively.

218 For this reason, interventions or health policies might consider increasing the intensity of AC .

219 For instance, promoting commuting by routes with higher average slope as a tool to increase

220 physical activity intensity in order to enhance adolescents' health-related fitness. Researchers

221 should take into account these findings during the ACS because it was showed a positive

222 relationship between average slope to lead the changes in their strength lower limbs and

223 cardiorrespiratory fitness.

224 In this line, numerous studies have examined specifically how the physical environment

225 affects ACS. The systematic review conducted by Chillón et al. (2011) tested that the cross-

226 sectional studies have consistently shown that distance is the strongest predictor of active 
227 transportation to school among children, with longer distances associated with lower rates of

228 active commuting. However, few intervention studies have taken into account the average slope.

229 Average slope could be considered as part of the inclusion criteria for intervention studies to

230 target students living within a walkable distance to school. Therefore, according to results, the

231 average slope should be as an inclusion criterion in the ACS.

232 Regarding the second hypothesis, the results did not confirm that body fat mediates the

233 relationship between the average slope and the strength lower limbs and cardiorrespiratory

234 fitness. Many studies have shown benefits of the ACS, related with reducing body fat, as a way

235 to prevent overweight and obesity of active commuters (Andersen et al., 2011; Muntaner-Mas et

236 al., 2018; Noonan et al., 2017). Despite these results, a negative association was found between

237 body fat and strength lower limbs and cardiorrespiratory fitness in active commuters. In line with

238 these results, the studies conducted by Mytton et al. $(2018$; 2016) and Poitras et al. (2016)

239 demonstrated that active travel was associated with reduced visceral adipose tissue, preventing of

240 cardio-metabolic disease. These authors revealed further evidence that promoting active travel

241 may contribute to improving cardio-metabolic health. In this sense, it is emphasised that adding

242 or including the average slope in active commuter into long-distance commutes is associated

243 with reduced adiposity. Enabling long-distance commuters to do this may require facilities that

244 enable walking or cycling in combination with car-use and public transport.

245 Finally, in relationship with the results and taking into account the previous literature

246 (Noonan et al., 2017; Villa-González et al., 2015), this research does not aim to study the

247 differences between active commuter groups, mixed commuter groups or passive commuter.

248 Nevertheless, including the environment elements (i.e. average slope) related with physical

249 fitness in the active commuters as an approach to enhance the knowledge about ACS in 
250 adolescents is a purpose to achieve. In this line, numerous studies have examined how the

251 physical environment affects active commuters. The systematic review conducted by Chillón et

252 al. (2011) tested that the cross-sectional studies have consistently shown that distance is the

253 important predictor of active transportation to school among children, with longer distances

254 associated with lower rates of active commuting. However, few of the intervention studies

255 included average slope in their study design or analyses, whereas average slope might be

256 considered as part of the inclusion criteria for intervention studies to target students living within

257 a walkable distance to school. Therefore, the average slope was should included as an inclusion

258 criterion, in the same way the distance and time in the ACS to achieve a closer and greater

259 understanding of ACS in previous studies. The results of the present investigation reinforce this

260 idea. Therefore, the main finding of this study is that the average slope to and from school is

261 positively associated with the levels of strength of the lower limbs and cardiorrespiratory fitness

262 of students classified as active commuters. In addition, the mediating effect of body fat in the

263 associations of the average slope to and from school with strength lower limbs and the average

264 slope to and from school with cardiorrespiratory fitness is another important finding.

265 This study presents some limitations. First, the use of a cross-sectional design does not

266 allow us to establish a causal relationship between the variables. Second, the temporal stability of

267 ACS was not assessed, as it is subject to climatological variables that are very difficult to control,

268 such as a prolonged period of rain, winter cold (Herrador-Colmenero et al., 2018). Finally, as

269 was previously indicated (Garcia et al., 2018), the biological maturation have a relevant

270 association with physical activity. Despite this issue, the authors recognize this limitation, so

271 individuals' biological maturation (prepubescent or post pubescent) was not assessed, and this

272 can make influence on the development of the physical fitness. The main strengths of this 
273 research is the use Google Earth to measure objectively the distance, time and average slope in

274 ACS, showing better precision and accuracy. In addiction, the $20 \mathrm{~m}$ shuttle run test was used to

275 measure cardiorrespiratory fitness as a health indicator in adolescents. In the future, it will be

276 interesting to take into account the average slope during ACS, because it has been shown to be

277 associated with the increase of the physical fitness. The implications of present study, highlight

278 the importance of average slope in ACS relationship between physical fitness in adolescents.

279 Therefore, the average slope should be considered a covariable in the future researches based on 280 ACS.

281

6. Conclusions

282

The present research has found positive associations between average slope and the body

283 fat in the ACS. Despite not being able to demonstrate the indirect effect of body fat between

284 average slope and strenght lower limbs, the results are relevant, since it has been possible to

285 confirm a negative association between the body fat and physical condition in active commuter 286 groups.

\section{Acknowledgements}

This study was funded by the European Community and Ministry of Economy of

Extremadura (IB16193). David Sánchez Oliva is supported by a Postdoctoral Research

Fellowship supported by the Region of Extremadura (REF TA18027). The work has been done as part of the multidisciplinary training program for the promotion of physical activity and other

292 healthy habits in sedentary adolescents. We gratefully acknowledge the financial support of the

293 Ministry of Economy and Infrastructures and European Community. The authors wish to thank

294 the schools, children and their parents who generously volunteered to participate in the study. 
295 We also acknowledge all the staff members involved in the fieldwork for their efforts and great 296 enthusiasm.

\section{Conflicts of Interest}

298 The authors declare no conflict of interest.

299 


\section{References}

301 Andersen LB, Wedderkopp N, Kristensen P, Moller NC, Froberg K, Cooper AR. 2011. Cycling

302 to school and cardiovascular risk factors: a longitudinal study. Journal of physical activity

$303 \quad \&$ health 8:1025-33.

304 Artero EG, España-Romero V, Castro-Piñero J, Ortega FB, Suni J, Castillo-Garzon MJ, Ruiz JR.

305 2011. Reliability of field-based fitness tests in youth. International Journal of Sports

$306 \quad$ Medicine 32:159-169. DOI: 10.1055/s-0030-1268488.

307 Batista FH, Cooper A, Audrey S. 2018. Associations of mode of travel to work with physical

308 activity, and individual, interpersonal, organisational, and environmental characteristics.

309 Journal of Transport \& Health 9:45-55. DOI: 10.1016/J.JTH.2018.01.009.

310 Bentler P. 1990. Comparative fit indexes in structural models. Psychological Bulleting 107:238311246.

312 Bentler PM, Bonett DG. 1980. Significance tests and goodness of fit in the analysis of $313 \quad$ covariance structures. Psychological Bulleting 88:588-606.

314 Browne M, Cudeck R. 1993. Alternative ways of assessing model fit. Sage focus editions:136$315 \quad 162$.

316 Carson V, Hunter S, Kuzik N, Gray CE, Poitras VJ, Chaput J-P, Saunders TJ, Katzmarzyk PT,

317 Okely AD, Connor Gorber S, Kho ME, Sampson M, Lee H, Tremblay MS. 2016.

318 Systematic review of sedentary behaviour and health indicators in school-aged children and 319 youth: an update. Applied Physiology, Nutrition, and Metabolism 41:S240-S265. DOI: $320 \quad$ 10.1139/apnm-2015-0630.

321 Castro-Piñero J, Artero EG, España-Romero V, Ortega FB, Sjöström M, Suni J, Ruiz JR. 2009.

322 Criterion-related validity of field-based fitness tests in youth: a systematic review. British 
journal of sports medicine 44:934-943. DOI: 10.1136/bjsm.2009.058321.

324 Chillón P, Evenson KR, Vaughn A, Ward DS. 2011. A systematic review of interventions for 325 promoting active transportation to school. International Journal of Behavioral Nutrition and Physical Activity 8:10. DOI: 10.1186/1479-5868-8-10.

327 Chillón P, Herrador-Colmenero M, Migueles JH, Cabanas-Sánchez V, Fernández-Santos JR, 328 Veiga ÓL, Castro-Piñero J. 2017. Convergent validation of a questionnaire to assess the 329 mode and frequency of commuting to and from school. Scandinavian Journal of Public Health 45:612-620. DOI: 10.1177/1403494817718905.

331 Chillón P, Martínez-Gómez D, Ortega FB, Pérez-López IJ, Díaz LE, Veses AM, Veiga OL,

332 Marcos A, Delgado-Fernández M. 2013. Six-year trend in active commuting to school in 333 Spanish adolescents. International Journal of Behavioral Medicine 20:529-537. DOI: 10.1007/s12529-012-9267-9.

Ehrström S, Tartaruga MP, Easthope CS, Brisswalter J, Morin JB, Vercruyssen F. 2017. Short trail running race: Beyond the classic model for endurance running performance. Medicine and Science in Sports and Exercise 50:580-588. DOI: 10.1249/MSS.0000000000001467.

Garcia C, Teles J, Barrigas C, Fragoso I. 2018. Health-related quality of life of Portuguese children and adolescents according to their biological maturation and volume of physical activity. Quality of Life Research 27:1483-1492. DOI: 10.1007/s11136-018-1822-7.

341 Herrador-Colmenero M, Harrison F, Villa-González E, Rodríguez-López C, Ortega FB, Ruiz JR, Jones AP, Chillón P. 2018. Longitudinal associations between weather, season, and mode of commuting to school among Spanish youths. Scandinavian Journal of Medicine \& Science in Sports 28:2677-2685. DOI: 10.1111/sms.13268.

Herrador-Colmenero M, Pérez-García M, Ruiz JR, Chillón P. 2014. Assessing modes and 
346 frequency of commuting to school in youngsters: a systematic review. Pediatric Exercise

347 Science 26:291-341. DOI: 10.1123/pes.2013-0120.

$348 \mathrm{Hu}$ L, Bentler PM. 1999. Cutoff criteria for fit indexes in covariance structure analysis:

349 conventional criteria versus new alternatives. Structural Equation Modeling: A

$350 \quad$ Multidisciplinary Journal 6:1-55. DOI: 10.1080/10705519909540118.

351 Ikeda E, Hinckson E, Witten K, Smith M. 2018. Associations of children's active school travel

352 with perceptions of the physical environment and characteristics of the social environment:

353 A systematic review. Health and Place 54:118-131. DOI:

$354 \quad$ 10.1016/j.healthplace.2018.09.009.

355 Larouche R, Saunders TJ, John Faulkner GE, Colley R, Tremblay M. 2014. Associations

356 between active school transport and physical activity, body composition, and cardiovascular

357 fitness: a systematic review of 68 studies. Journal of Physical Activity and Health 11:206-

358 227. DOI: $10.1123 /$ jpah.2011-0345.

359 Leger LA, Mercier D, Gadoury C y, Lambert J. 1988. The multistage 20 metre shuttle run test

360 for aerobic fitness direct assessment of the bioenergetic qualities on ice of young hockey

361 players. Article in Journal of Sports Sciences 6:93-101. DOI:

$362 \quad 10.1080 / 02640418808729800$.

363 Lubans DR, Boreham CA, Kelly P, Foster CE. 2011. The relationship between active travel to

364 school and health-related fitness in children and adolescents: a systematic review.

365 International Journal of Behavioral Nutrition and Physical Activity 8:5. DOI:

$366 \quad 10.1186 / 1479-5868-8-5$.

367 Martin A, Boyle J, Corlett F, Kelly P, Reilly JJ. 2016. Contribution of walking to school to

368 individual and population moderate-vigorous intensity physical activity: systematic review 

and meta-analysis. Pediatric Exercise Science 28:353-363. DOI: 10.1123/pes.2015-0207.

370

McCormack GR, Shiell A. 2011. In search of causality: a systematic review of the relationship between the built environment and physical activity among adults. International Journal of Behavioral Nutrition and Physical Activity 8:125. DOI: 10.1186/1479-5868-8-125.

Mora-Gonzalez J, Rodríguez-López C, Cadenas-Sanchez C, Herrador-Colmenero M, EstebanCornejo I, Huertas-Delgado FJ, Ardoy DN, Ortega FB, Chillón P. 2017. Active commuting to school was inversely associated with academic achievement in primary but not secondary school students. Acta Paediatrica, International Journal of Paediatrics 106:334-340. DOI: 10.1111/apa.13679.

Muntaner-Mas A, Herrador-Colmenero M, Borràs PA, Chillón P. 2018. Physical activity, but not active commuting to school, is associated with cardiorespiratory fitness levels in young people. Journal of Transport and Health 10:297-303. DOI: 10.1016/j.jth.2018.05.004.

Mytton OT, Ogilvie D, Griffin S, Brage S, Wareham N, Panter J. 2018. Associations of active commuting with body fat and visceral adipose tissue: a cross-sectional population based study in the UK. Preventive Medicine 106:86-93. DOI: 10.1016/j.ypmed.2017.10.017.

Mytton OT, Panter J, Ogilvie D. 2016. Longitudinal associations of active commuting with wellbeing and sickness absence. Preventive Medicine 84:19-26. DOI:

$$
\text { 10.1016/J.YPMED.2015.12.010. }
$$

Noonan RJ, Boddy LM, Knowles ZR, Fairclough SJ. 2017. Fitness, fatness and active school commuting among liverpool schoolchildren. International Journal of Environmental Research and Public Health 14. DOI: 10.3390/ijerph14090995.

Poitras VJ, Gray CE, Borghese MM, Carson V, Chaput J-P, Janssen I, Katzmarzyk PT, Pate RR, Connor Gorber S, Kho ME, Sampson M, Tremblay MS. 2016. Systematic review of the 
392 relationships between objectively measured physical activity and health indicators in

393 school-aged children and youth. Applied Physiology, Nutrition, and Metabolism 41:S197-

394 S239. DOI: 10.1139/apnm-2015-0663.

395 Preacher KJ, Hayes AF. 2008. Asymptotic and resampling strategies for assessing and

396 comparing indirect effects in multiple mediator models. In: Behavior Research Methods.

397 879-891. DOI: 10.3758/BRM.40.3.879.

398 Ramírez-Vélez R, García-Hermoso A, Agostinis-Sobrinho C, Mota J, Santos R, Correa-Bautista

399 JE, Amaya-Tambo DC, Villa-González E. 2017. Cycling to school and body composition,

400 physical fitness, and metabolic syndrome in children and adolescents. The Journal of

$401 \quad$ Pediatrics 188:57-63. DOI: 10.1016/j.jpeds.2017.05.065.

402 Rodríguez-Rodríguez F, Pakomio Jara O, Kuthe NM, Herrador-Colmenero M, Ramírez-Vélez R, 403 Chillón P. 2019. Influence of distance, area, and cultural context in active commuting:

$404 \quad$ Continental and insular children. PLOS ONE 14:e0213159. DOI:

$405 \quad$ 10.1371/journal.pone.0213159.

406 Ruiz JR, Romero VE, Castro Piñero J, Artero EG, Ortega FB, Cuenca García M, Pavón DJ,

407 Chillón P, Rejón JG, Mora J, Gutiérrez A, Suni J, Sjöstrom M, Castillo MJ, Ruiz JR. 2011.

408 Artículo especial Batería ALPHA-Fitness: test de campo para la evaluación de la condición

409 física relacionada con la salud en niños y adolescentes. Nutrición Hospitalaria 26:1210-

$410 \quad$ 1214. DOI: $10.3305 / \mathrm{nh} .2011 .26 .6 .5270$.

411 Sallis JF, Cerin E, Conway TL, Adams MA, Frank LD, Pratt M, Salvo D, Schipperijn J, Smith

412 G, Cain KL, Davey R, Kerr J, Lai P-C, Mitáš J, Reis R, Sarmiento OL, Schofield G,

413 Troelsen J, Van Dyck D, De Bourdeaudhuij I, Owen N. 2016. Physical activity in relation to 414 urban environments in 14 cities worldwide: a cross-sectional study. The Lancet 387:2207- 
2217. DOI: 10.1016/S0140-6736(15)01284-2.

416 Slingerland M, Borghouts LB, Hesselink MKC. 2012. Physical Activity energy expenditure in

417 dutch adolescents: contribution of active transport to school, physical education, and leisure

418 time activities. Journal of School Health 82:225-232. DOI: 10.1111/j.1746-

419 1561.2012.00691.x.

Steiger JH. 1990. Structural model evaluation and modification: an interval estimation approach. Multivariate Behavioral Research 25:173-180.

Transport M of. 2014. Comparing travel modes: New Zealand Household Travel Survey. :2010_ 2013.

Tremblay MS, Barnes JD, González SA, Katzmarzyk PT, Onywera VO, Reilly JJ, Tomkinson GR, Aguilar-Farias N, Akinroye KK, Al-Kuwari MG, Amornsriwatanakul A, Aubert S, Belton S, Gołdys A, Herrera-Cuenca M, Jeon JY, Jürimäe J, Katapally TR, Lambert E V., Larsen LR, Liu Y, Löf M, Loney T, López y Taylor JR, Maddison R, Manyanga T, Morrison SA, Mota J, Murphy MH, Nardo N, Ocansey RTA, Prista A, Roman-Viñas B, Schranz NK, Seghers J, Sharif R, Standage M, Stratton G, Takken T, Tammelin TH, Tanaka C, Tang Y, Wong SH. 2016. Global matrix 2.0: Report card grades on the physical

433 Veitch J, Carver A, Salmon J, Abbott G, Ball K, Crawford D, Cleland V, Timperio A. 2017.

434 What predicts children's active transport and independent mobility in disadvantaged 435 neighborhoods? Health and Place 44:103-109. DOI: 10.1016/j.healthplace.2017.02.003.

436 Vernillo G, Savoldelli A, Skafidas S, Zignoli A, La Torre A, Pellegrini B, Giardini G, Trabucchi 437 P, Millet GP, Schena F. 2016. An extreme mountain ultra-marathon decreases the cost of 
uphill walking and running. Frontiers in Physiology 7:530. DOI: 10.3389/fphys.2016.00530.

440 Villa-González E, Rodríguez-López C, Barranco-Ruiz Y, Cabezas-Arévalo LF, Chillón P. 441 2016a. Evaluación de la concordancia de dos métodos para determinar la distancia del 442 desplazamiento activo al colegio en escolares. Nutrición Hospitalaria 33. DOI: 10.20960/nh.283.

444 Villa-González E, Ruiz J, Chillón P, Villa-González E, Ruiz JR, Chillón P. 2015. Associations 445 between active commuting to school and health-related physical fitness in spanish school446 aged children: a cross-sectional study. International Journal of Environmental Research and Public Health 12:10362-10373. DOI: 10.3390/ijerph120910362.

Villa-González E, Ruiz JR, Ward DS, Chillón P. 2016b. Effectiveness of an active commuting school-based intervention at 6-month follow-up. The European Journal of Public Health 26:272-276. DOI: 10.1093/eurpub/ckv208.

Yang Y, Ivey SS, Levy MC, Royne MB, Klesges LM. 2016. Active Travel to school: findings

452 from the survey of US health behavior in school-aged children, 2009-2010. Journal of School Health 86:464-471. DOI: 10.1111/josh.12395.

454 Yuan K-H, Bentler PM. 2000. Three likelihood-based methods for mean and covariance 455 structure analysis with nonnormal missing data. Sociological methodology 29:165-200. DOI: $10.1017 / \mathrm{CBO} 9781107415324.004$. 
Figure 1

Flow chart of participants according to the mode of travel.

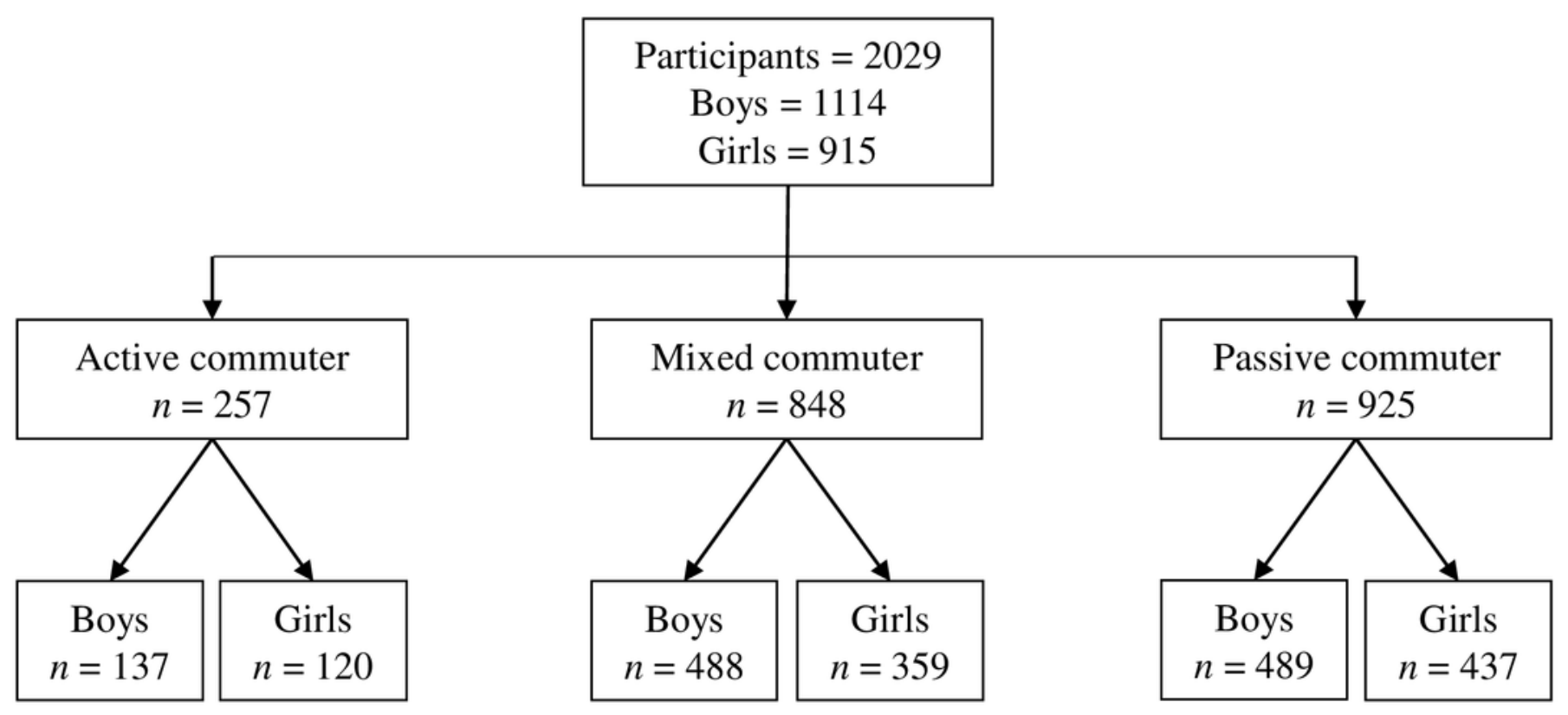


Figure 2

Standardized solution of the model.

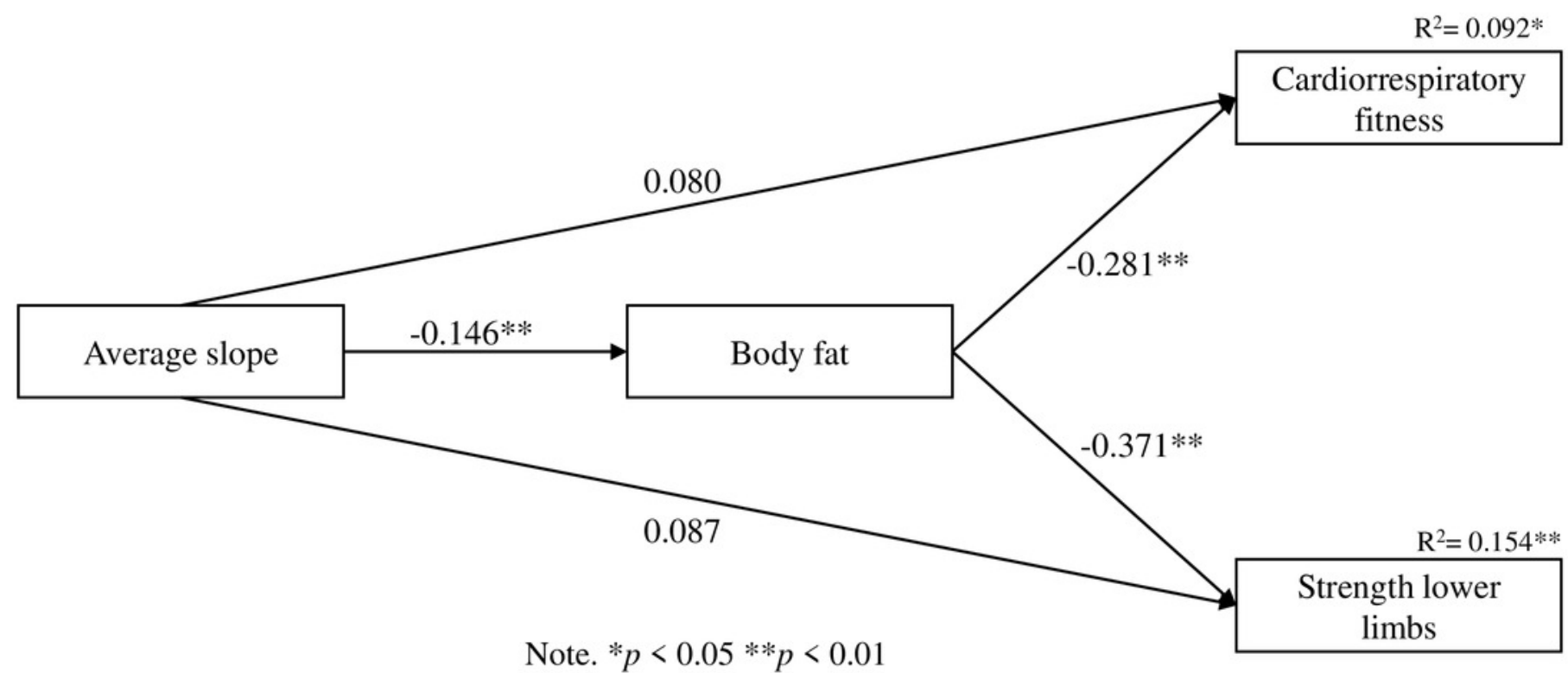




\section{Table 1 (on next page)}

Descriptive analysis of the study variables and sex differences. 
1 Table 1. Descriptive analysis of the study variables and sex differences

\begin{tabular}{lccccccccc}
\hline & \multicolumn{2}{c}{ Total } & \multicolumn{2}{c}{ Boys } & \multicolumn{2}{c}{ Girls } & \multirow{2}{*}{$t$} \\
\cline { 2 - 8 } & \multicolumn{2}{c}{$M$} & $S D$ & $M$ & $S D$ & $M$ & $S D$ & & \\
\hline$n_{\text {total }}$ & \multicolumn{2}{c}{256} & \multicolumn{2}{c}{137} & \multicolumn{2}{c}{119} & & & \\
Age (years) & 13.20 & 0.05 & 13.25 & 1.03 & 13.15 & 0.88 & 0.090 & 0.80 \\
Weight (kg) & 54.11 & 0.74 & 55.61 & 12.10 & 52.31 & 9.79 & 0.079 & 2.37 \\
Tricipital fold (mm) & 17.56 & 0.48 & 16.39 & 8.83 & 19.00 & 6.24 & $\mathbf{0 . 0 0 1}$ & -2.68 \\
Subescapular fold (mm) & 13.40 & 0.49 & 12.76 & 7.54 & 14.20 & 6.10 & 0.121 & -1.66 \\
Strength of the lower & 156.28 & 1.87 & 168.05 & 31.26 & 142.12 & 23.53 & 0.052 & 6.93 \\
limbs (cm) & 8.09 & 2.43 & 8.03 & 2.45 & 8.17 & 2.42 & 0.424 & -0.45 \\
Number of trips/week & 1703.50 & 770.62 & 1732.12 & 860.74 & 1670.83 & 654.83 & 0.853 & 0.63 \\
Distance (m) & 20.44 & 9.24 & 20.78 & 10.32 & 20.05 & 7.85 & 0.853 & 0.63 \\
Time (min) & 2.93 & 2.12 & 3.12 & 2.69 & 2.71 & 1.14 & 0.104 & 1.52 \\
Average slope (\%) & 26.47 & 0.64 & 25.86 & 11.61 & 27.26 & 6.90 & $\mathbf{0 . 0 0 0}$ & -1.17 \\
Body Fat (\%) & 41.81 & 0.36 & 43.93 & 5.95 & 39.29 & 4.14 & $\mathbf{0 . 0 0 0}$ & 6.66 \\
Cardiorrespiratory & & & & & & & &
\end{tabular}


Table 2 (on next page)

Indirect effects. 
1 Table 2. Indirect effects.

$\beta \quad$ SE $\quad$ Bootstrap 95\% CI $\quad p$

\begin{tabular}{lcccc}
\hline Average slope $\rightarrow$ Strength lower limbs & & & & \\
Total Effect & 0.141 & 0.075 & {$[0.018 ; 0.265]$} & 0.060 \\
Direct Effect & 0.087 & 0.087 & {$[-0.056 ; 0.231]$} & 0.317 \\
Indirect Effect (via Body Fat) & 0.054 & 0.036 & {$[-0.006 ; 0.114]$} & 0.138 \\
\hline Average slope $\rightarrow$ Cardiorrespiratory fitness & & & & \\
Total Effect & 0.121 & 0.114 & {$[-0.067 ; 0.309]$} & 0.290 \\
Direct Effect & 0.080 & 0.135 & {$[-0.142 ; 0.302]$} & 0.552 \\
Indirect Effect (via Body Fat) & 0.041 & 0.032 & {$[-0.011 ; 0.093]$} & 0.195 \\
\hline
\end{tabular}

2 Note. $\beta$ = standard coefficient; SE: estimation deviation 3 